\title{
To Be or Not To Be a Behaviorist? Facial Recognition Systems and Critical Knowledge
}

\author{
Mathieu Cornélis \\ University of Namur \\ (Belgium) - CITA \\ mathieu.cornelis@fundp.ac.be
}

\author{
Nathalie Grandjean \\ University of Namur \\ (Belgium) - CITA \\ ngrandje@fundp.ac.be
}

\author{
Claire Lobet-Maris \\ University of Namur \\ (Belgium) - CITA \\ clo@info.fundp.ac.be
}

\begin{abstract}
In this paper, we assess the possibility of a critical knowledge of technology. In the case of facial recognition systems, 'FRS', we argue that behaviorism underlies this technology, and analyze the debate about behaviorism to show the lack of consensus about its theoretical foundations. In particular we analyze the structure of knowledge generated by FRS as affected by a technological behaviorism. Our last point is a suggestion to use the concept of 'critical knowledge', which we borrow from Ladrière, to question and challenge the technological finalities and the foundational scientific theory underlying FRS.
\end{abstract}

\section{Introduction}

Our paper is part of the activities developed by the MIAUCE project, a European research project involving university researchers, industrials and marketing staff [1]. This project raises the question of multi-modal technology. We here focus on the scenario of the design and use of interactive web-TV technology, scenario that entails among others the design and use of facial recognition systems, hereafter 'FRS', so as to link facial physical stimuli and emotions when a certain kind of web information arises. In this project, societal, ethical and legal issues of this kind of technology are explored by a research group from the social sciences of the University of Namur. One of the main questions which emerge is the possibility to found a technological innovation more acceptable and which takes into account ethical and legal issues in its design.

In order to reach these aims, we propose in this paper to analyze the possibility to apply to technology what Ladrière has called 'critical knowledge'. Critical knowledge, as we will see it, would create the conditions for the possibility for ethical attitudes in technological development and scientific knowledge. We here develop as example facial recognition technologies, hereafter 'FRS', to illustrate the feasibility of the application of a critical knowledge analysis in the field of engineering ethics.

In order, we first explore the theoretical foundations at the basis of facial recognition systems. We show how the idea of behaviorist theoretical attitude underlines the design of the facial recognition systems under examination here. We also categorize types of behaviorist theories according to their radicalism, so as to render as possible epistemological assessment of impacts on facial recognition systems. This will lead to the suggestion that a critical knowledge analysis is possible to reflect on behaviorism as pre-formatting theory underlying facial recognition systems.

Lastly, we assess the conditions of possibility for a critical knowledge analysis.

\section{Facial Recognition Systems: A Behaviorist System?}

\subsection{Behaviorism: Definition}

According to Sellars, behaviorists are researchers exploring behaviors as tools to be interpreted to acquire knowledge and understanding of individual psychologies. To these researchers, Sellars argues, behaviors are the starting point for an enquiring process of drawing and testing hypotheses about "psychological events" [2]. If we follow this definition, behaviorists are thus theorists on individual psychologies calling in to behaviorism as tool for exploration.

Behaviorism, as a doctrine, involves some different claims. This can be shown through a classification of the kinds of behaviorism according to their historical roots, and, especially, according to their finalities. We here distinguish between 'methodological' behaviorism, 'psychological' or 'radical' behaviorism and 'analytical' or 'philosophical' behaviorism [3]. 
First, 'methodological' behaviorists claim that mental states ought not to be looked at in empirical studies. Rather, methodological behaviorists turn their attention to the scientific conduct of psychology, the latter being seen as the science of behaviour, not of the mind. Historically this trend started with the logical positivism developed by the Vienna Circle during the 1920s and 1930s [4], which called for the unification of all scientific endeavours, be they on the natural, human or technological worlds.

Second, following on Vienna logical positivism too, 'analytical' behaviorists take a more philosophical stance as regards to the meaning and semantics of mental terms. These behaviorists tend to be more concerned about the structure of our mental concepts and the possibility to eliminate some of them. That is, they work by looking out for mental concepts that could be eliminated and replaced with, translated into, physical concepts [5].

Third, 'psychological' behaviorists prefer to explain human and animal behaviors solely in terms of external physical stimuli. The more 'radicals' among them go up to sustaining scientific theories in which mental states are explain by physical states (included environmental influence). John Locke (1632-1704) and David Hume (1711-1776) are the foremost British empiricists at the roots of this thought.

\subsection{Facial Recognition and Methodological Behaviorism}

With visages being seen as the mirror to the mind, facial recognition systems, hereafter 'FRS', are often used in multimodal analysis of (potential) users' and consumers' behaviors. It is the case for the MIAUCE project. The procedure at stake here is as follows. First, the camera captures a face, and fits it with a virtual mask. This mask is then prepared for the interpretation of facial expressions through by a frame made of coding points being attached to specific areas and lines on the face. This particular coding frame is then compared to measures calculated on a large sample of population expressing specific chosen emotions. Thereafter, a particular facial expression under examination is decoded and interpreted using a grammar of basic emotions such as anger, sadness, happiness, etc. There is also a system for the quantification of this intensity of these emotions on the facial capture.

Our argument here is that FRS is embodiment of a methodological behaviorism approach to individual subjectivity. Although engineers may not be psychologists, they translate into the devices the methodological behaviorism concepts implicit to the results obtained by the psychologists consulted during the elaboration stage of the devices. In the specific context of MIAUCE, this process is particularly strong due to the close-knit collaboration between behaviorist psychologists and engineers in charge of the design of FRS. FRS, as they are to be used in the MIAUCE technologies, can thus be seen as an expression of the particular psychological methodology of methodological behaviorism. Related, we wish also to argue that this type of system and the related technology lead to a new kind of behaviorism, technological behaviorism, which we explore and question throughout the rest of this paper as regards to its actual knowledge-production capacity and as regards to its ethical implications.

\section{Behaviorism: A Fallacy?}

Behaviorism has long been in the centre of heated debates, for it is often challenged as to its usefulness as well as to the risk of the false conclusions it can generate about mental states and mind and sensible experiences such as emotions

\subsection{Epistemological Critics of Behaviorism}

A first critique originates in the concept of reinforcement much used by behaviorists [6]. Reinforcement means an increase of the strength of a response following on changes in the direct environment, by a causal and deterministic relation. In the MIAUCE technology, that is interactive web$\mathrm{TV}$, this concept is very present. Indeed the basic model at work implies the presupposition that facial expressions and emotions are directly caused by the sole change in the visualized TV images. With the 'environment', that is the TV, being cast as an exogenous factor causing deterministically changes in emotions and facial expression, the MIAUCE FRS is very much in line with this behaviorist notion of reinforcement. We would think that there are issues here with a potential denial of individual subjectivities and of the personal and social representations of environments.

This shows, we would argue, in some studies by philosophers of mind when they explore and exploit the philosophical concept of 'quale', qualia in plural form [7]. In our understanding, qualia can help showing off incompleteness inherent to the concept of reinforcement. Qualia are a philosophical concept referring the properties of sensitive experience. These properties of sensitive experience may be defined as 
follows. They are not communicable except by direct experience, they are not relational, they are not comparable with others qualia, and they can only be understood directly by consciousness. In other words, these qualia, which form the real sensitive experience, are showing out only through the mental, thinking experience. This is why it is impossible or incomplete to describe any mental state related to a sensitive experience, such as 'fear' only in physical words, let not say a computerized model of emotions.

Our concerns here is that, in that sense, behaviorism implies a deterministic view of the human being, who is reduced to his/her physical features. In the behaviorist frame described above, both the autonomy of the individuals and the subjectivity are denied. Against this objection, some behaviorist psychologists insist on their practice of cross-examinations using both physical and environmental stimuli. However some among them also counter-argue, claiming that physical features can not necessarily express individual subjectivity. Thus, there are major ethical issues raised by the criticisms about the lack of epistemological outputs from behaviorist theories - which we explore later. Still it may useful however to check out on the potential scientific contributions from the latter.

\subsection{To Take or Not To Take a Behaviorist Stance?}

One first reason to defend a behaviorist approach to mental states, and one that is well exploited by behaviorists, is the vigorous desire to understand the nature of humans. With psychologists providing plenty of material underlining the links between beliefs and emotions on the one hand and kinds of behavior on the other, it is indeed tempting to reduce mental states to behaviors so as to explore the working of the human mind. In that sense, the popularity of behaviorism is thus connected to a quite natural desire to understand the structure of human being, and, especially, the mind, in understandable terms. For providing answers to the question as 'how' about the human mind, behaviorism, as a reductionist theory of mental state, permits to work ahead and generate understanding.

Another reason to defend defense of behaviorism emerges from the works of Skinner [8], an opponent to simply inner mental explanatory causes of behaviors. In his opinion, only behaviorists are capable of stating on the innate rules by which emotions and bodily expressions can be explored. That is, mental states must be explained in terms which do not involves mental states themselves.
Skinner's argument originates in the circularity paradoxes to be found in mental definition. How could we explain mental state without using mental states itself? If we explain mental states in such a circular way, we can only end up developing an innate approach and analysis of mental states. This position is quite a negative defense - it pushes behaviorism by stating on a defect it does not have -, and as a result, we would argue that he somehow lost sight of the consequences and implications of behaviorism itself. Indeed, Skinner, who has been severely criticized, goes in other places up to proposing a social worldview from his views on behaviorism, suggesting paradoxes and subjective problems in his behaviorism, among others an aversion to free will and autonomous being [9].

\section{Facial Recognition Systems, Engineers and Critical Knowledge}

Earlier in this paper, we have shown how FRS are closely although implicitly linked to behaviorism. This was shown to especially the case to the methodological behaviorism. What this has suggested too is that a specificity of behaviorism is that to become potentially integrated in a technology, through the particular structure of knowledge its use in the design of the technology entails. Thus, the technological degree of behaviorism displayed in FRS also entails a particular way to think, a technological knowledge. At this effect, we would argue here for the possibility for, and use of, what we call 'critical knowledge'.

\subsection{The goal-directedness of technological engineering?}

When the doctrine of behaviorism came in to the field of FRS technology, we would argue that a teleological turning point was reached, as this advent entails another structure of knowledge. By teleological, we mean here that a sense of purpose is inherent to technology, and that the structure of knowledge is directed towards specific ends, be they financial, political, economical, industrial, etc.

Indeed scientists' activities, as we said before, are geared towards looking for answers to 'how' of the world's operation, i.e. how the mind thinks or how algorithm can involve behavior. So as to explore what the incursion of ends and teleology means in the domain of a technological development, we would argue to think about technological engineering as an activity that tends to answer questions of the 'forwhat' [10]. In this case, the purpose-geared aspects 
of technological engineering are obvious; technological design can be seen as the gradual "construction of means more and more efficient to realize some purposes" [11]. For this reason, we argue that facial recognition systems require reflecting about their structure and features. We present briefly in the next section the conditions to set up for making possible critical knowledge Due to the teleogical turning point in the field of technological design pointed above, there is a serious need to take into account the ethical issues raised up by these activities. Moreover, ethical issues, as we have said, also entail reflecting upon the early doctrine that permits the making of the technology, i.e. in this case about FRS behaviorism.

\subsection{Critical Knowledge}

To be thorough, our ethical reflection has to be concerned with the whole of the process of the technological design, from the early behaviorist doctrine involved to the later implementation of technology into the society. Towards this end, it may be useful, we suggest, to think about scientific knowledge, alongside, Jean Ladrière, philosopher and scientist, as 'critical knowledge' [12]. In Ladrière's terms, critical knowledge means that, during the process of technological innovation, a habit of regular overviewing advancement is needed to assess and judge impacts of technological practices. "A critical knowledge," Ladrière underlines, "ought be able to self assess, to identify and discern within itself what is relevant according to the very activity by which it is constituted, and, through this, become able to evaluate on its own the value and boundaries of the validity of what it ends up proposing" [13]. Thus, "a critical attitude covers at the same time on science, and the ways it tackles with reality, and on technology, and the ways it tends towards improving the human condition" [14].

Ladrière's 'critical knowledge' concept is applicable here, we would argue. Indeed, the earlier presentation of behaviorism frame and its implementation in FRS technology shows how each interacted with one another and start off such a critical knowledge process, as well as the epistemological critiques that have shown the strains between enthusiastic defenders and skeptical critiques. Especially, critical knowledge here means a critical attitude about our activities at each level, and also about the knowledge of the early theoretical implication of our technological activities.

\section{Closing Comments}

Throughout the paper, we have endeavored to show that a critical understanding of the processes at work in the making of a technology is crucial so as to start in earnest the exploration of its impacts and consequences. In particular, while finishing up with critical knowledge, we have pointed out that an analysis using this latter concept and focused on the societal and ethical issues of technology too implies the need for reflecting upon the processes that permit the design of a technology and render it acceptable in society. Now, is this to say that engineers and, in general, scientists ought to have their daily life filled with reflections on ethical, philosophical, societal and legal considerations? Is it that technologists ought to practice two or three more human-focused trades in same time as they design technology? No. We only mean to suggest that technological development and scientific questioning involves at some point to face up with a broader vision about what is being done, what for it is being done and, maybe also, why it is needed.

\section{References}

\section{[1] See http://www.miauce.org}

[2] W. Sellars, "Philosophy and the Scientic Image of Man", Science, Perception, and reality, Routledge \& Kegan Paul, New-York, 1963, pp. 1-40.

[3] G., Graham, "Behaviorism”, Stanford Encyclopedia of Philosophy, http://plato.stanford.edu/entries/behaviorism/, Stanford, 2007.

[4] O., Neurath, Le développement du Cercle de Vienne et l'avenir de l'empricisme logique, Hermann \& Co, Paris, 1936.

[5] About the philosophical theories of "eliminativism" of mental concept see, per example, P., Churchland, Matter and Consciousness, MIT Press/Bradford Books, Massachusetts, 1984.

[6] About a formalisation of "reinforcement" which shows a defender of behaviorism at work, see P.R., Killeen, "Mathematical Principles of reinforcement", Behavioral and brain Sciences, 17 (1), 1994, pp. 105-172.

[7] See for example, the real interesting following paper: N., Thomas, "What is it Like to be a Bat?", in Mortal Questions, Cambridge University Press, Cambridge, 1979, pp. $165-180$. 
[8] B. F., Skinner, Science and Human Behavior, Macmillan, New-York, 1953 and B. F., Skinner, About behaviorism, Vintage, New-York, 1974.

[9] About the main and most successful critics of behaviorism, mainly about linguistic behaviorism, see N., Chomsky, "Review of Verbal Behavior", Language, 35, pp. 26-58 and also N., Chomsky, "The case Against B. F. Skinner", New-York review of Books, 30, pp. 18-24.

[10]http://www.espace-

citoyen.be/site/index.php?EsId=1\&Module=modproduit\&Indice=1-14-35, B. Hespel's interview.

[11] T., Dedeurwaerdere, "la dimension éthique dans la sphère de la rationalité technologique: normes, contextes et arrière-plans", in Les Carnets du Centre de Philosophie du Droit, $\mathrm{n}^{\circ} 82$, 2000, p. 2. We traduce.

[12] J., Ladrière, Les enjeux de la rationalité. Le défi de la science et de la technologie aux cultures, AubierMontaigne / UNESCO, Paris, 1977 and also J., Ladrière, L'éthique dans l'univers de la rationalité, Artel/Fides, Namur/Québec, 1997.

[13] J., Ladrière, Les enjeux de la rationalité. Le défi de la science et de la technologie aux cultures, AubierMontaigne / UNESCO, Paris, 1977, p. 128. We traduce.
[14] B., Feltz, "Démocratie technique, inventivité éthique et modernité critique", in B. Feltz and alii, Ethique, technique et démocratie, Academia Bruylant, 2007, p. 10. We traduce.

\section{Acknowledgement}

Part of the research for this paper has been made in the course of the MIAUCE research project (CNRS Lille, University of Glasgow, University of Amsterdam, University of Namur, Sylis, Tilde and Visual-Tools) funded by the European Commission. This paper also benefited from discussions held with Yves Poullet, Denis Darquennes and Antoinette Rouvroy of the Information technology and Law research Center (CRID) of the University of Namur. The authors also wish to acknowledge Sandra Mols who kindly agreed to review and improve the linguistic quality of this paper. 